\title{
AGENTES/ATORES ENVOLVIDOS NA INSTITUCIONALIZAÇÃO DE POLÍTICAS PÚBLICAS DE EDUCAÇÃO AMBIENTAL NO BRASIL E A NECESSIDADE DO DIÁLOGO ENTRE ELES
}

\author{
Ana Clara Nery-Silva*
}

RESUMO: Buscando panoramas gerais sobre pesquisas em educação ambiental, o presente estudo investigou agentes/atores envolvidos nos processos de elaboração e implementação de políticas públicas federais de educação ambiental no Brasil. Foram encontrados diferentes agentes/ atores, divididos em duas categorias: governamentais e não-governamentais. $\mathrm{Na}$ primeira, estão presidentes, ministros, deputados federais, ministérios e secretarias de educação. Já na segunda, encontram-se comissões, conselhos e comitês da sociedade civil (incluindo movimentos sociais e organizações nãogovernamentais), educadores e corporações econômicas. Conclui-se que é necessário um maior diálogo entre os agentes/ atores envolvidos em cada uma das etapas para que as políticas elaboradas façam sentido ao serem implementadas em diferentes espaços educativos. Considera-se, também, que é necessário que a sociedade civil e os educadores sejam mais convidados a construir as políticas públicas educacionais, de maneira mais participativa, dialógica e democrática.

Palavras-chave: Educação ambiental; Políticas públicas; Agentes/atores.

\begin{abstract}
Seeking overviews on research in environmental education, this study investigated agents/ actors involved in elaboration and implementation processes of federal public policies for environmental education in Brazil. Was found different agents/ actors, organized in two categories: governmental and non-governmental. In the first, are presidents, ministers, deputies, ministries and departments of education. In the second, can be found commissions, councils and committees of civil society (including social movements and nongovernmental organizations), educators and economic corporations. We conclude its necessary for more dialogue between the agents/ actors involved in each step, to the elaborate public policies that can make sense when they are implemented in different educational spaces. It is considered, also, that is necessary than civil society and educators are more invited to build educational public policies, making this by a participative, dialogical and more democratic way.
\end{abstract}

Keywords: Environmental education; Public policies; Agents/actors.

"Mestre em Educação pelo Instituto de Biociências da Universidade Estadual Paulista "Júlio de Mesquita Filho" (Unesp) - Campus de Rio Claro. 


\section{SOBRE EDUCAÇÃO}

A educação pode ser entendida como prática social necessária ao processo de formação humana (CAVALARI; SANTANA; CARVALHO, 2006), sendo que ao mesmo tempo em que é necessária à formação dos sujeitos, ela também é uma prática realizada por eles. Assim, como resultante da atividade humana deve-se considerar (como para qualquer outra ação ou prática dos seres humanos), que ela não possui uma única direção, um único sentido (SANTANA, 2005, p.1): não há uma forma única nem um único modelo de educação (BRANDÃO, 1981).

As tantas direções e sentidos possíveis para a educação podem se refletir em diferentes adjetivações para a mesma, sendo uma delas a educação ambiental. A educação ambiental reflete uma complexa problemática das relações entre sociedade e natureza e das relações estabelecidas entre os próprios seres humanos. Desta forma, práticas em educação ambiental podem subsidiar reflexões e ações que norteiem a superação da crise socioambiental (NERY-SILVA, 2015).

$\mathrm{Na}$ história da educação a temática socioambiental é relativamente recente e só começou a dar indícios de certa perenidade a partir da década de 1980 (SANTANA, 2005), mesma década na qual as práticas educacionais ligadas à educação ambiental começaram a se consolidar (DIAS, 1991), especialmente no âmbito escolar. Juntamente com estas práticas começaram a se realizar também as primeiras pesquisas em educação ambiental no Brasil.

Desde então pesquisas que investigam a educação ambiental cresceram consideravelmente, com o número de trabalhos produzidos aumentado muito desde o fim da década de 1990 até o início dos anos 2000 (FRACALANZA et al, 2005; REIGOTA, 2007). Como resultado do expressivo crescimento de pesquisas (em especial, dissertações e teses), surgiram investigações sobre a própria produção de pesquisa, chamadas de pesquisas de "estado da arte", "estado do conhecimento"1 (FERREIRA, 2002) ou metapesquisas (KATO, 2014).

1 Pesquisas de "estado da arte" não são restritas à educação ambiental, ocorrendo nas diversas áreas das ciências, graças à tendência geral da crescente produção científica, especialmente nas ciências sociais e humanas (GODOY, 1995). 
Estas são investigações que buscam compreender os conceitos e enfoques descritos e analisados nas produções acadêmicas, sendo importantes à área educacional e à educação ambiental por pelo menos três motivos (NERY-SILVA, 2015). O primeiro deles diz respeito à sistematização de dados, permitindo a formação de panoramas gerais sobre a produção de pesquisas na área (CARVALHO; TOMAZELLO; OLIVEIRA (2009); FRACALANZA et al. (2005); MEGID NETO (2009).

O segundo deles refere-se à configuração de características sobre temáticas específicas (BITAR, 2010; KATO, 2014; PALMIERI, 2011; REIS, 2013; SOUZA, 2012; ZUPELARI, 2014). E o terceiro e último, corresponde à sistematização de dados de eventos científicos nos quais as pesquisas podem ser debatidas, sendo um exemplo o Encontro de Pesquisa em Educação Ambiental (EPEA), que trata especificamente desta área do conhecimento (CAVALAR; SANTANA; CARVALHO, 2006; FERRARO-JÚNIOR, 2012; GUIMARÃES, OLABARRIAGA, TONSO, 2009; KAWASAKI et al., 2009; SANTANA, 2014).

Voltar-se à pesquisa em educação ambiental pode auxiliar na compreensão sobre as "características pedagógicas, culturais, sociais e políticas que a constituem e que são influenciadas por ela, criando assim um corpo de conhecimentos sobre este assunto" (NERY-SILVA, 2015, p. 16).

É neste contexto que se organiza o projeto "A EDUCAÇÃO AMBIENTAL NO BRASIL: análise da produção acadêmica (dissertações e teses)", também chamado de "Projeto EArte". ${ }^{2}$ Este projeto busca sistematizar a produção de pesquisas sobre educação ambiental no país, vislumbrando contextos de produção e temáticas desenvolvidas (CARVALHO et al., 2013).

Um dos temas a ser investigado dentro da educação ambiental é o tema de políticas públicas, com possíveis contribuições à educação e ao próprio fazer político. Por isso, o trabalho aqui apresentado analisou dissertações e teses de educação ambiental relacionadas às políticas públicas, investigando

2 Desenvolvido de maneira interinstitucional, o projeto objetiva mapear investigações acadêmicas (dissertações e teses) em educação ambiental já produzidas no Brasil, tendo como produto desse mapeamento um catálogo on-line que conta com 2111 fichas de diferentes dissertações e teses em educação ambiental defendidas entre os períodos de 1981 e 2009. 
agentes/ atores ${ }^{3}$ envolvidos nos processos de institucionalização de políticas públicas federais de educação ambiental.

Após longo processo de triagem dentro do catálogo do Projeto (disponível no link www.earte.net), o corpus documental contou com 5 pesquisas, focadas em investigar os processos de elaboração e implementação de políticas públicas federais de educação ambiental no país.

Para análise do corpus utilizou-se a Análise de Conteúdo, proposta por Bardin (2011). Um breve resumo de todo o procedimento de busca é trazido na figura $1^{4}$ :

Figura 1. Sistematização do caminho metodológico trilhado.



Fonte: Nery- Silva (2015).

Já o quadro abaixo permite observar algumas características dos trabalhos contidos no corpus documental. A sigla "cód." refere-se ao cadastro no catálogo do Projeto EArte, que pode ser gratuitamente consultado:

\footnotetext{
3 Deve-se esclarecer que "atores/ agentes" são usados no masculino, mas referem-se à pessoas de ambos os gêneros, sendo aqui utilizados em um gênero apenas por facilidade de leitura.

${ }_{4}^{4}$ Para compreender melhor o processo de triagem e seleção do corpus documental desta pesquisa, sugere-se a leitura de Nery-Silva (2015).
} 
Quadro 1: Características dos trabalhos selecionados para compor o corpus documental da investigação.

\begin{tabular}{|c|c|c|c|c|c|}
\hline Código & Autor & Título da pesquisa & IES & Ano & Objetivo da pesquisa \\
\hline $\begin{array}{c}\text { Tr. } 1 D- \\
\text { cód. } 4424\end{array}$ & $\begin{array}{l}\text { José Leitão } \\
\text { de } \\
\text { Albuquerque } \\
\text { Filho }\end{array}$ & $\begin{array}{l}\text { A Educação Ambiental para a } \\
\text { sustentabilidade dos recursos } \\
\text { hídricos. }\end{array}$ & UFSC & 2003 & $\begin{array}{l}\text { Analisar a efetivação dos comitês de bacias hidrográficas, do Conselho Nacional } \\
\text { de Recursos Hídricos em esferas estaduais e municipais, vinculando-os à PNEA } \\
\text { e ProNEA. Observar a ação da educação ambiental na efetivação dos Comitês } \\
\text { de Bacias Hidrográficas, ligados à Política Nacional de Recursos Hídricos } \\
\text { (PNRH) }\end{array}$ \\
\hline $\begin{array}{l}\text { Tr. } 15 D \text { - } \\
\text { cód. } 4847\end{array}$ & $\begin{array}{l}\text { Lilian } \\
\text { Medeiros de } \\
\text { Mello }\end{array}$ & $\begin{array}{l}\text { A questão do formalismo no } \\
\text { discurso oficial da Educação } \\
\text { Ambiental. }\end{array}$ & UTFPR & 2001 & $\begin{array}{l}\text { Verificar a presença de "formalismo idealizado" no discurso oficial da educação } \\
\text { ambiental, analisando e interpretando os Parâmetros curriculares nacionais } \\
\text { (PCN) e a Lei 9.795/ } 99 \text { (que regulamenta a PNEA), incluindo suas elaborações } \\
\text { e implementações enquanto política pública. }\end{array}$ \\
\hline $\begin{array}{l}\text { Tr. 18D - } \\
\text { cód. } 6256\end{array}$ & $\begin{array}{l}\text { Nelcilene da } \\
\text { Silva } \\
\text { Palhano }\end{array}$ & $\begin{array}{l}\text { Representações sociais de meio } \\
\text { ambiente dos atores que atuam na } \\
\text { formulação e execução das } \\
\text { políticas de Educação Ambiental. }\end{array}$ & UFAM & 2006 & $\begin{array}{l}\text { Analisar as concepções de meio ambiente nas políticas públicas de Educação } \\
\text { Ambiental e nas representações de atores sociais que formularam e executam } \\
\text { essas políticas em diferentes níveis federativos. }\end{array}$ \\
\hline $\begin{array}{l}\text { Tr. } 23 T \text { - } \\
\text { cód. } 496\end{array}$ & $\begin{array}{l}\text { Irineu } \\
\text { Tamaio }\end{array}$ & $\begin{array}{c}\text { A política pública de educação } \\
\text { ambiental: sentidos e contradições } \\
\text { na experiência dos } \\
\text { gestores/educadores da Diretoria } \\
\text { de Educação Ambiental do } \\
\text { Ministério do Meio Ambiente - } \\
\text { gestão do governo Lula (2003- } \\
\text { 2006). }\end{array}$ & UNB & 2007 & $\begin{array}{l}\text { Interpretar e problematizar as concepções de educação ambiental e } \\
\text { sustentabilidade materializadas nos documentos oficiais através da ação de } \\
\text { gestores/ educadores que formularam/ executaram as políticas públicas de } \\
\text { educação ambiental da Diretoria de Educação Ambiental do Ministério do Meio } \\
\text { Ambiente no primeiro mandato do presidente Lula (2003-2006). }\end{array}$ \\
\hline
\end{tabular}




\begin{tabular}{ccccc}
\hline Tr. 24D - & João Paulo & O financiamento público da Política \\
cód. 8144 & $\begin{array}{c}\text { Sotero de } \\
\text { Vasconcelos }\end{array}$ & $\begin{array}{c}\text { Nacional de Educação Ambiental: } \\
\text { do veto do artigo 18 às novas } \\
\text { estratégias de financiamento. }\end{array}$ & UNB & 2008 \\
& & $\begin{array}{c}\text { Analisar as trajetórias do Fundo Nacional do Meio Ambiente (FNMA), incluindo } \\
\text { as alterações na sua elaboração, como o veto do artigo 18 (que institui seu } \\
\text { financiamento) e as consequências para o financiamento da educação } \\
\text { ambiental na implementação da PNEA com este artigo vetado. }\end{array}$ \\
\hline
\end{tabular}

Fonte: Nery- Silva (2015). 


\section{SOBRE AS POLÍTICAS PÚBLICAS}

Se a educação está diretamente ligada aos rumos sociopolíticos de uma sociedade, é preciso então entender o que são e como se dão as políticas públicas educacionais. Por sua vez, para entender políticas públicas é preciso imaginar que desde o início do convívio em sociedade, foi preciso estabelecer acordos que permitissem uma coexistência minimamente pacífica. Como as sociedades se tornaram, pouco a pouco, cada vez mais complexas emergiu, então, a necessidade de acordos que são igualmente mais complexos (NERYSILVA, 2015).

Contratos relativos às esferas sociais e políticas fundamentam a organização das sociedades, permitindo que os membros que dela participam possam conviver de maneira harmônica, na medida do que lhes for possível. Nesse caminho, é necessário "compreender os grupos e os interesses existentes em cada sociedade, de maneira que os acordos façam uma mediação entre as tensões existentes entre estes grupos, nos diferentes momentos históricos vividos" (NERY-SILVA, 2015, p. 58).

Desta forma, as políticas públicas se formam para organização das sociedades e os acordos delas resultantes vêm se constituindo enquanto estratégias de e para organização social.

As políticas públicas podem ser entendidas como ações e escolhas governamentais (DYE, 1984) dadas em diferentes níveis federativos (SOUZA, 2003, 2007), voltadas para setores específicos da sociedade (HOFLING, 2001) e que estão articuladas à estrutura mais global que a sociedade constrói para si (AZEVEDO, 2004) (NERY- SILVA, 2015).

Estas ações governamentais corroboram com diferentes formas, funções e opções ideológicas reveladas pelos dirigentes governamentais em diferentes tempos históricos (GIRON, 2008; SANTOS, 1999) (NERY- SILVA, 2015).

Apesar da extrema importância governamental, não se pode esquecer que numa democracia representativa os dirigentes governamentais são eleitos pela sociedade como seus representantes. A prerrogativa é que as opções ideológicas assumidas pelos dirigentes reflitam as opções da sociedade que os elegeu, e não apenas a destes dirigentes enquanto sujeitos individuais (NERY- 
SILVA, 2015).

Assim, a sociedade civil - com educadores, movimentos sociais e outros setores que a compõem - deve ter seus interesses atendidos pelos dirigentes que os representam quando na institucionalização de uma política pública, em especial, mas não somente, aquelas que lhes afetarão diretamente.

Contrários à ideia de um protagonismo apenas governamental, Biasoli (2015) e Sorrentino (2011) ressaltam a importância da participação de diferentes agentes/ atores para que estas políticas públicas se estabeleçam e as mudanças, de fato, se concretizem. Juntamente com Nery-Silva (2015), destaca-se a importância do diálogo e do empoderamento de diferentes setores sociais, para que estes percebam que não apenas os dirigentes governamentais e seus assessores devem decidir sobre as políticas públicas a serem institucionalizadas.

As políticas teriam por intuito organizar social e politicamente as diversas esferas envolvidas num fazer coletivo, incluindo a área educacional. Porém, a que educação nos referimos quando pensamos nas políticas públicas criadas? Pensar em políticas públicas educativas é refletir sobre o tipo de educação e sociedade almejadas. Deste modo, o estudo das políticas públicas ajudaria a

\footnotetext{
(...) compreender para quais problemas foram formuladas; que conflitos tentam medir/ resolver; qual a trajetória seguida nas diferentes etapas de sua institucionalização; que papel os atores/indivíduos envolvidos ocupam; que instituições e grupos de interesse estão envolvidos nas decisões ou que poderão ser afetados por elas; bem como que processos em que assuntos privados se tornam públicos e vice-versa (CAPELLA, 2006, 2007; SOUZA, 2006, 2007) (NERY-SILVA, 2015, p. 20).
}

Compreendendo a importância dos agentes envolvidos na institucionalização das políticas, o presente estudo buscou refletir sobre os grupos trazidos como agentes/ atores envolvidos nas etapas de elaboração e implementação de políticas públicas federais de educação ambiental, a partir de pesquisas já realizadas sobre o assunto.

As principais políticas públicas federais de educação ambiental presentes nas pesquisas foram a Política Nacional de Educação Ambiental PNEA - (lei no 9.795/99), o Programa Nacional de Educação Ambiental (ProNEA) (1994) e o Programa Nacional de Formação de Educadores 
Ambientais (ProFEA) (2006). Estas, por sua vez, apareceram juntamente à Lei de Diretrizes e Bases da Educação (LDB, 9.304/ 96) e os Parâmetros Curriculares Nacionais (PCN) (1997).

Segundo modelos de análise de políticas públicas, basicamente são três os processos que as institucionalizam: elaboração, implementação e avaliação. Porém, aqui se priorizou os processos de elaboração e implementação, graças à ausência de dados sobre a avaliação das políticas nas pesquisas selecionadas para análise.

\section{AGENTES/ATORES NAS POLÍTICAS PÚBLICAS FEDERAIS DE EDU- CAÇÃO AMBIENTAL}

A partir das investigações do corpus documental, agentes /atores envolvidos na elaboração e implementação de políticas públicas federais de educação ambiental foram organizados em dois grupos: um com agentes advindos de esferas governamentais (a) e outro com agentes vindos de esferas não-governamentais (b).

(a). Como agentes/ atores governamentais estão inclusos os sujeitos ou grupos que representam autoridades oficiais, pessoas que ocupam cargos governamentais. Os policy makers são "aqueles que definem as políticas em nível nacional e internacional" (Tr.18D, p. 13), trazidos nos textos como mais importantes na elaboração de políticas.

Os Tr.15D e Tr.24D sugerem que o fato de estâncias governamentais serem consideradas como os agentes mais importantes da elaboração é assegurado no artigo 225 da Constituição Federal, o qual ressalta "de forma mais contundente o papel do poder público na definição de políticas públicas que tratem do meio ambiente, que promovam a educação ambiental e o engajamento da sociedade" (Tr.24D, p. 122).

A figura do Presidente materializou- se nos textos em cinco nomes, correspondentes a diferentes gestões governamentais, com os três primeiros sendo José Sarney (Tr.24D), Fernando Collor de Mello (Tr.24D) e Itamar Franco (Tr.24D), os três tendo sido citados na assinatura de documentos legais, mas sem grandes debates sobre contribuições ou perdas para a área durante seus mandatos. 
Já Fernando Henrique Cardoso apareceu em quatro trabalhos, com seu nome encontrado nos anexos da Política Nacional de Recursos Hídricos (PNRH, lei 9.433/97) (Tr.1D), junto à PNEA (Tr.1D; Tr.15D) e no decreto 4.281/2002 (que regulamenta à PNEA, no Tr.1D).

Nos Tr.1D e Tr.15D seu nome foi apenas citado, enquanto o Tr.24D trouxe críticas e questionamentos sobre ações ocorridas em seus mandatos como críticas à decisão do Presidente da República em ter vetado o artigo [18 do Projeto de Lei 3.792/93, que dispunha sobre a Política Nacional de educação ambiental], juntamente com os Ministérios da Educação e do Meio Ambiente. O veto do artigo 18 da PNEA em 1999 (instrumento que estabelecia o destinamento de $20 \%$ da verba recolhida por crimes ambientais à educação ambiental do país), foi trazido com justificativas não plausíveis, uma vez que em 2003 o mesmo artigo foi apresentado como o PL1.016/03 e "aprovado sem ressalvas" (Tr.24D, p 183)

O quinto nome foi de Luiz Inácio Lula da Silva visto, de um lado, apresentando contribuições à educação ambiental em seu mandato, destacando-se, especialmente, o financiamento da mesma com aprovação do PL 1.016/03, a qual instituiu uma fonte de recursos à programas e projetos de educação ambiental.

O Tr.23T constatou contribuições do primeiro mandato deste presidente (2003-2006) na gestão e desenvolvimento de políticas públicas de educação ambiental, propondo uma gestão mais participativa, com as contribuições de educadores/ especialistas enquanto gestores destas políticas no Ministério do Meio Ambiente .

Trechos de críticas ao seu mandato também foram encontrados como um reflexo de frustrações às propostas de educação ambiental que não se desenvolveram como prometido na campanha governamental, inclusive por contradições internas, nas quais “(...) a visão hegemônica de desenvolvimento na política pública do governo Lula sobressaiu em relação à outra visão interna mais sustentabilista [que] pode ser entendida na compreensão de alguns setores do movimento socioambiental" (Tr.23T, p. 36).

Vale ressaltar que nos textos os Presidentes apareceram apenas enquanto elaboradores de políticas públicas, sem que estes participassem 
diretamente de seus processos de implementação. Dilma Roussef não apareceu nos textos graças ao recorte temporal da investigação, já que as pesquisas analisadas foram defendidas até 2009.

A figura de Ministros (as) do Meio Ambiente apareceu em três diferentes nomes, representando por José Sarney Filho (Tr. 1D; Tr.15D) e José Carlos Carvalho (Tr.1D), sendo que nenhuma das pesquisas discorreu sobre contribuições destes dois gestores, mesmo quando recortes históricos foram feitos sobre a trajetória destas políticas (Tr.23T; Tr.24D).

O terceiro e mais frequente nome foi o da ex-ministra Marina Silva (gestão 2003-2008) (Tr.1D; Tr.24D), com contribuições à uma gestão que compreendia a educação ambiental como assunto para além do Ministério do Meio Ambiente e fruto de uma gestão mais democrática:

Segundo a ministra de Meio Ambiente, Marina Silva, em discurso pronunciado na abertura da II Conferência Nacional de Meio Ambiente, em 2005, o MMA entende que as políticas públicas "devem ser formuladas num processo aberto, horizontalizando, com a participação de todos os segmentos da sociedade" (BRASIL, 2005c, p. 16) (Tr.23T, p. 51, grifo nosso).

O Ministro da Educação também apareceu ligado às políticas de educação ambiental com o nome de Paulo Renato de Souza (gestão 1995 2002) (Tr.1D; Tr.15D), ambos sem discorrer sobre suas ações.

Outro agente foi o deputado federal, sendo que apenas o nome de Fábio Feldmann (então deputado federal pelo estado de São Paulo), apareceu, ao se ressaltar a importância deste na criação do Projeto de lei (PL) 3.792/93 que dispunha sobre a educação ambiental, instituindo a Política Nacional de Educação Ambiental (Tr.24D). O deputado acompanhou-a até ela se tornar uma política pública, processo que tramitou por cerca de seis anos.

Os Ministérios do Meio Ambiente e da Educação também foram trazidos como representantes governamentais que auxiliariam na elaboração e implementação das políticas públicas de educação ambiental no país, especialmente compondo o Órgão Gestor (OG) da PNEA (Tr.23T; Tr.24D): 
Coordenadoria-Geral de Educação Ambiental do Ministério da Educação (CGEA/MEC) formam o Órgão Gestor da PNEA (OG$P N E A)$. Os dois órgãos têm a atribuição legal de formular $e$ implementar políticas de EA em âmbito federal, nos marcos legais da PNEA (Tr.23T, p. 14-15).

Destaca-se a importância de um trabalho conjunto entre estes dois ministérios, criando uma visão múltipla sobre a educação ambiental, devendo o OG ser reconhecido "por outras áreas do Governo Federal como exemplo a ser seguido" (Tr.24D, p. 182).

Outros representantes entendidos como agentes governamentais são as secretarias de educação (SEDUCs) (Tr.18D), entidades próximas ao ambiente escolar de ensino e que junto aos educadores foram trazidas como grandes responsáveis pela implementação de políticas no ensino formal, por exemplo, através de programas e projetos.

Estas podem fazê-los através de convênios e parceiras, por exemplo, com institutos e universidades, como no Tr.18D, no qual "(...) convênio e parceria entre SEDUC/INPA/UFAM (...) [foram] realizados através de projetos de Educação Ambiental nas escolas estaduais" (Tr.18D, p. 73). As SEDUCs seriam responsáveis por articular diversos agentes, como institutos (como 0 INPA - Instituto Nacional de Pesquisas Amazônicas) ou universidades (como a UFAM - Universidade Federal de Manaus).

Por fim, acredita-se que se outros recortes tivessem sido feitos (como, por exemplo, em âmbito estadual ou municipal) outras esferas governamentais poderiam ter sido referenciadas (como, por exemplo, vereadores, prefeitos, etc.)

(b). Como agentes/atores não-governamentais estão sujeitos ou grupos que não representam diretamente autoridades oficiais/ cargos governamentais, mas que têm opiniões consideradas na institucionalização de uma política pública. O primeiro deles são comissões, conselhos e comitês da sociedade civif , considerados como instâncias formadas por representantes da sociedade

\footnotetext{
${ }^{5}$ A matriz habermasiana (Jürgen Habermas) considera sociedade civil como "instituições e formas associacionais que requerem interação comunicativa para sua reprodução e que confiam primariamente em processos de integração social para ação coordenada dentro de suas fronteiras" (PINHEIRO, 2015, p. 89). Ou seja: são as associações de pessoas integradas e que interagem de maneira coordenada nos limites dos grupos nos quais se inserem.
} 
civil que dialogam com representantes do poder público, buscando uma gestão coletiva na resolução de problemas.

Entre estas se encontram as Comissões Interinstitucionais Estaduais de Educação Ambiental (CIEAs), as quais são "instaladas em âmbito estadual, com representatividade do poder público e da sociedade, cujo papel é formular e acompanhar as políticas e programas estaduais de EA, em consonância com a PNEA e o ProNEA" (Tr. 23T, p. 61).

As CIEAS também foram consideradas como "um dos colegiados relativo ao meio ambiente e à educação ambiental” (Tr.24D, p, 178), ao compor um comitê assessor do Órgão Gestor da PNEA, auxiliando também na formulação de Programas e Projetos (Tr.18D), como o a Agenda 21 ou a Comissão de Meio Ambiente e Qualidade de Vida (Projeto Com-Vidas).

No Tr. 1D a participação da sociedade foi observada nos Comitês de Bacias Hidrográficas (CBHs), que são “(...) o espaço para compartilhar as questões hídricas com os representantes do poder público, usuários e sociedade". (Tr.1D, p. 104). A integração entre os CBHs e a educação ambiental possibilitaria a observação de problemas ambientais sob a ótica da complexidade, incentivando "a participação e a cidadania" dos sujeitos (Tr.1D, p. 143).

O mesmo trabalho considerou os $\mathrm{CBHs}$ enquanto espaços implementadores de ações da educação ambiental, já que neles a sociedade civil participou da implementação de duas políticas públicas: PNEA (enquanto comitê assessor do Órgão Gestor) e PNRH (Política Nacional de Recursos Hídricos), demonstrando a importância destes colegiados como espaços de diálogo que auxiliam numa gestão coletiva para resolução de problemas ligados à questão ambiental.

O Tr.15D apresenta fragmentos textuais que criticam a ausência da sociedade na formulação dos PCN, quando este desconsiderou "a participação da comunidade na avaliação das situações críticas, das necessidades e dos desejos de mudança (...)" (Tr.15D, p. 67). Questionamentos são válidos no tocante à implementação desta política, indicando que é “(...) necessário que se perca o caráter de isolamento que existe entre os poderes públicos e os principais envolvidos na sua implementação, ou seja, os pais, os órgãos 
diretivos das escolas, os professores e os interessados na educação" (Tr.15D, p. 70).

Neste trecho, a sociedade civil, representada pelos pais e outros possíveis "interessados na educação" é considerada um dos principais agentes ligados à implementação das políticas no ensino formal (junto ao professorado e demais membros da comunidade escolar), reforçando a necessidade destes membros encabeçarem processos decisórios, tendo "suas necessidades e desejos" considerados para a institucionalização de políticas públicas.

A importância da participação da sociedade civil na implementação do ProNEA foi trazida afirmando-se que neste Programa “(...) é fundamental o apoio à (...) implementação de políticas descentralizadas, no âmbito dos estados e municípios, bem como a criação de mecanismos de financiamento que envolvam o poder público e a sociedade civil" (Tr24D, p. 146).

Assim, a sociedade estaria 'legalmente assegurada' enquanto um dos personagens a ser consultado na institucionalização da educação ambiental nas diferentes esferas do ensino. Inclusive, a sociedade seria uma das instâncias avaliadoras do seu financiamento; ou seja, a destinação de recursos para as ações de educação ambiental a serem implementadas também deveria ter o aval da sociedade civil.

Isso justificaria criação do Fundo Brasileiro de Educação Ambiental (FUNBEA), tendo a participação da sociedade civil junto aos educadores e ao governo na gestão de recursos voltados à programas e projetos de educação ambiental.

Organizações não governamentais (ONGs) componentes do Terceiro setor social, compreendidas aqui enquanto "associações comunitárias, movimentos sociais, fundações, etc., corresponderiam ao setor privado sem fins lucrativos, o público não estatal ou o público, porém privado" (PINHEIRO, 2015, p. 86) também apareceram (Tr.13D; Tr.15D).

A presença destas nos processos de elaboração de políticas públicas é oficialmente assegurada na Seção III do artigo 13 da PNEA, que insere as ONGs como agentes participativos das políticas públicas de educação ambiental, considerando que a PNEA “(...) propõe um constante exercício de transversalidade para internalizar a educação ambiental no conjunto do 
governo, nas entidades privadas e no terceiro setor (...)" (Tr.23T, p. 86).

Os movimentos sociais - considerados como advindos da sociedade civil uma vez que podem ser compreendidos enquanto ações sociais coletivas de caráter sociopolítico e cultural que tornam viável formas distintas da população organizar-se e expressar suas demandas (GOHN, 2008) - também apareceram.

Nos cinco trabalhos os movimentos sociais - em especial ligados à dimensão ambiental ${ }^{6}$ e o movimento de contracultura (Tr.1D; Tr.23T; Tr.24D) apareceram associados à trajetória de emergência da educação ambiental, ainda que não tenham se encontrado nomes ou dados mais contundentes que comprovassem que estes são agentes que participariam efetivamente da elaboração de políticas públicas ligadas à educação ambiental.

Mas eles apareceram junto à educadores no 'Tratado de Educação Ambiental para Sociedades Sustentáveis e Responsabilidade Global', ao se recomendar que os signatários do Tratado devam "reivindicar dos governos que destinem um percentual significativo do Produto Nacional Bruto para a implantação de programas de educação ambiental em todos os setores da administração pública, com a participação direta de ONGs e movimentos sociais"(Tr.24D, p.145).

O trabalho supracitado afirmou ainda que os movimentos ambientalistas precisam passar por "enormes avanços, (...) no sentido de tornar-se um movimento menos elitista, capaz de percolar, de forma permanente, todo tecido social" (Tr.24D, p. 179).

O próprio movimento deve buscar maior aproximação com o "tecido social", com a realidade dos grupos que compõem a sociedade. Trabalhando juntos, ambos podem auxiliar na construção de um novo paradigma socioambiental, superando a crise vigente e a dicotomia dos movimentos ambientalistas do 'Norte e do Sul' (divisão proposta para definir países "ricos/pobres" ou "desenvolvidos/em desenvolvimento") (Tr.18D), que também afastam o movimento do "tecido social.

Superando generalizações, concorda-se com os autores ao se pensar

6 Este movimento recebeu as designações de movimento ecológico (Tr.18D, p. 26; Tr. 23T, p. 125) ou ambientalista (Tr.18D, p. 26; Tr.23T, p. 145; Tr.24D, p. 8) ou ambientalismo (Tr.15D, p. 64; Tr.23T, p. 53 p. Tr.24D, p. 36). 
que os movimentos ambientalistas devem contemplar ideais de contestação mais efetivos e coerentes ao sistema vigente, inclusive buscando inserção junto às diferentes esferas de ensino (formal, informal, não formal).

Outros agentes não governamentais importantes foram os especialistas (chamados por Kindgon (2003 apud CAPELLA, 2006) de policy community) (Tr.1D; Tr.24D), que aparecem na figura de pesquisadores, assessores parlamentares, acadêmicos, funcionários públicos, entre outros (CAPELLA, 2006) que podem contribuir como consultores à institucionalização de políticas.

A presença dos especialistas enquanto assessores na elaboração de políticas públicas de educação ambiental está garantida na organização dos membros do OG, que consta, por exemplo, com o Conselho Federal da Ordem dos Advogados do Brasil (OAB), a Sociedade Brasileira para o Progresso da Ciência, o Conselho Nacional do Meio Ambiente, o Conselho Nacional de Educação, entre outros.

Dúvidas, porém, pairam sobre a escolha destes especialistas, uma vez que a OAB é membro do Comitê e outros Conselhos de relevante atuação no campo não estão representados, como o Conselho Federal de Biologia (CFBio) e o Conselho Federal de Engenharia e Arquitetura e Agronomia (Confea) (Tr.24D). Vale a reflexão sobre possíveis interesses contidos na efetivação desses assessores.

Segundo os textos, os especialistas foram primordiais na idealização dos PCN, assessorando dirigentes governamentais nos pressupostos desta política num processo de discussão em âmbito nacional (1995-96), "do qual participaram docentes de universidades públicas e particulares, técnicos de (...) instituições representativas de diferentes áreas do conhecimento, especialistas (...)”. (BRASIL, 1996, p. 17) (Tr.15D, p. 20).

Com relação à PNEA, o Tr.24D, por sua vez, sugeriu que deveria haver maior união entre educadores e intelectuais, pois considera que apenas os últimos tenham sido devidamente consultados e aos primeiro "a PNEA foi imposta". Sugere ainda que caberia "aos educadores ambientais se organizarem técnica e politicamente para sugerirem aos parlamentares de suas regiões de atuação a proposição de uma nova PNEA" fazendo uma "aglutinação dos educadores ambientais" (Tr.24D, p. 136) juntamente aos 
intelectuais, visando amplamente a PNEA em todo país.

Os especialistas foram encontrados mais especificamente enquanto agentes do processo de elaboração de políticas públicas, sem grandes debates sobre sua participação nos processos de implementação das mesmas.

Os educadores apareceram na figura dos professores, gestores e/ou educadores ambientais, referenciando espaços formais, não formais e informais de ensino. De maneira geral, os educadores não foram os personagens mais considerados no processo de elaboração, com exceção do Tr.23T. Neste, cinco educadores discorreram sobre suas contribuições à Diretoria de Educação Ambiental do Ministério do meio Ambiente (DEA/ MMA), ocupando cargos técnicos e de direção e tendo a "responsabilidade de pensar, elaborar, negociar e implementar um programa de política pública em EA" (Tr.23T, p. 31).

Nos demais trabalhos a participação dos educadores aparece muito mais ligada aos processos de elaboração de projetos e planos do que de políticas propriamente ditas (Tr.18D; Tr.24D). Supunha-se que a presença dos educadores enquanto elaboradores das políticas públicas seria mais frequente nos trabalhos, isso, pois são eles quem "vivenciam" a educação ambiental nas diferentes esferas de ensino.

Para 0 ensino formal, 0 trabalho de educadores enquanto implementadores da educação ambiental estaria assegurado via PRONEA, PNEA e PCN (Tr.1D). Segundo tais documentos, a educação ambiental vem sendo implementada no ensino formal desde 1996 quando

\footnotetext{
(...) a temática ambiental [inseriu-se] nos Parâmetros Curriculares Nacionais/MEC, de 1996, como tema transversal, e busca sua efetivação através dos Parâmetros em Ação - Meio Ambiente/MEC 2001, incentivando a inserção dos temas ambientais nos currículos de todas as disciplinas e nos projetos pedagógicos das unidades escolares do ensino fundamental (Tr.1D, p.21, grifo nosso).
}

Ao se falar do âmbito do ensino formal, encontraram-se referências aos educadores como "aqueles que estão executando essas políticas" (Tr.18D, p. 14), os "executores das políticas" (Tr.18D).

Entende-se que a implementação é umas etapas de suma importância para a institucionalização de políticas públicas, pois é a etapa na qual diretrizes 
(e ideologias) asseguradas em documentos legais se materializam em ações concretas na sociedade na qual forma instituídas. O problema, porém, advém do fato dos educadores muitas vezes serem considerados apenas como executores da política (Tr.18D), correndo-se o risco de afastá-los do processo de elaboração destas.

Isso poderia ser contraditório e perigoso se considerarmos que estes agentes são aqueles que de fato vivenciam o cotidiano educacional, tendo aptidão para pensarem, junto a outros agentes e decisores, possibilidades pedagógicas viáveis, devendo, assim, ter sua participação assegurada, inclusive nos processos de elaboração de políticas educacionais.

Assim, é necessário incluir os educadores nos debates sobre todas as etapas de institucionalização de políticas públicas educacionais, garantindo que os mesmos sejam incluídos na formulação de políticas educacionais, para que não recebam as propostas acabadas quando são inseridos apenas "no fim da linha":

Foi observado que o processo de elaboração dos PCN (...) [acabou] designando ao professorado um papel burocrático, no fim da linha (SAVIANI, 199, p. 26), (...) desconsiderando a participação da comunidade [escolar] na avaliação da situação das situações críticas, das necessidades e dos desejos de mudança (...)" (Tr.15D, p. 66-67, grifo nosso).

Entende-se que os educadores têm concepções e práticas que os caracterizam como "profissionais militantes" (Tr.23T, p. 162), devendo-se considerar as ideias e ideais trazidos por estes profissionais e inserindo suas opiniões na formulação de políticas:

(...) todos esses ideários subjetivos podem ser interpretados como um novo momento na história da institucionalização da EA, em que esse grupo de gestores/educadores foi portador simbólico de grande parte das aspirações acumuladas na trajetória de luta democrática e emancipatória da EA no Brasil. Para mim, a política pública da DEA ganhou novos contornos. (Tr.23T, p. 164, grifo nosso).

Porém, pode ser necessário um processo formativo aos educadores (Tr.18D; Tr.23T) para que estes estejam aptos à contribuir com as diferentes etapas das políticas educacionais. Esta capacitação/formação seria tão importante que se instituiu sete anos depois da PNEA um Programa 
responsável pela formação de educadores nas mais diversas esferas do ensino, com o Profea. Tal Programa busca "fomentar processos de formação continuada em educação ambiental, formal e não formal, dando condições para a atuação [de educadores ambientais] nos diversos setores da sociedade" (BRASIL, 2005, p. 39) (Tr.23T, p. 94).

Junto aos educadores em diferentes esferas de ensino, foi frequente a presença dos coletivos educadores, apresentados como "um conjunto de representantes de instituições que atuam em processos formativos e que se aproximam no sentido de possibilitar uma formação permanente, participativa, continuada e voltada à totalidade de habitantes de um determinado território" (BRASIL, 2005, p. 8) (Tr.23T, p. 98).

Estes coletivos seriam espaços que funcionariam como "(...) uma instância representativa de interlocução e de referência para as ações educadoras locais" (BRASIL, 2005, p. 9) (Tr.,3T, p. 98), traduzindo-se num

\begin{abstract}
“(...) espaço no qual ministérios e instituições com atuação nos temas da educação ambiental, (...) emancipação e participação social poderão articular suas políticas de formação de gestores públicos, conselheiros, técnicos, educadores, professores e lideranças em geral, assim como qualificar seus foros de participação social e suas intervenções educacionais voltadas à criação ou aprimoramento de estruturas e espaços que tenham potencialidade de atuação como educadoras na direção da sustentabilidade (BRASIL, 2005) (Tr.23T, p. 98, grifo nosso).
\end{abstract}

Ali, diferentes agentes interagem, de maneira a valorizar a participação destes nos processos de constituição de uma educação ambiental mais próxima da educação popular (Tr.23T, p. 98). Através da educação popular, diversos saberes são considerados, podendo construir uma autêntica esfera participativa, de modo que as discussões de temas públicos sejam entrelaçadas a conceitos e conteúdos que possam ser formalizados em um currículo elaborado e contextualizado localmente (KATO, 2007).

Assim, é preciso reforçar a importância de coletivos educadores na multiplicação da educação ambiental, aliando-a à educação popular e buscando alcançar saberes e demandas advindos da população em geral. Inclusive, no que diz respeito ao apoio financeiro à estas instituições, incluindoas em fundos de captação de recursos como o FunBEA (Tr.24D). 
As corporações econômicas foram os últimos agentes nãogovernamentais ligados à institucionalização das políticas, materializando-se nos textos enquanto "agentes de mercado". Mesmo que possa parecer confuso, é preciso compreender que os indivíduos que controlam estas corporações econômicas, de maneira geral, buscam inserí-las na lógica do capital produtivo, talvez o grande fator que leve à crise socioambiental vigente.

Exemplos destas corporações se materializam nos fragmentos abaixo:

\begin{abstract}
A educação passa a ser considerada um investimento e, nesta perspectiva de ajuste ao mercado, caracteriza-se no contexto do capitalismo globalizado, como um subsetor da economia (...)[e]deve se pautar por princípios econômicos. Assim (..) o Banco Mundial, dado o seu poder econômico, embora não seja a única instância a determinar as políticas educacionais, tem assumido um papel de destaque ao oferecer sugestões de reformas nos sistemas educacionais (Tr.18D, p. 43, grifo nosso).

A iniciativa do MEC de definir os Parâmetros Curriculares Nacionais (...) está vinculada à nova Lei de Diretrizes e Bases da Educação (...); as discussões que culminaram na elaboração e publicação da LDB e do PCN se iniciaram (...) com a participação o Brasil na Conferência Mundial de Educação para Todos, convocada pela Unesco, Unicef, PNUD e Banco Mundial, realizada em 1990, em Jontien, na Tailândia (Tr.15D, p. 18, grifo nosso)
\end{abstract}

A presença de entidades internacionais como a Unesco, a Unicef e o Banco Mundial enquanto agentes presentes em encontros que tratam de políticas educacionais, deve nos deixar atentos quanto aos reais interesses destas na educação.

Em âmbito nacional, as corporações econômicas apareceram influenciando decisões governamentais, como em exemplo trazido pelo Tr.23T, no qual a Confederação Nacional da Indústria (CNI) pressionou ativamente o Congresso Nacional para que não fosse aprovado o Projeto de Lei 1.016/03 (incluindo o artigo 19-A à Lei 9.795/99/ PNEA) que propunha que fabricantes e distribuidores de produtos veiculados em embalagem descartável deveriam destinar $10 \%$ do valor despendido com a propaganda do produto à educação ambiental.

Sugere-se que "muito provavelmente a Confederação Nacional da Indústria trata dos temas afetos às suas atividades diretamente com deputados e senadores", inclusive porque "muitos destes são empresários" (Tr.24D, p. 153), o que dificultaria a negociação com gestores no sentido de almejar uma 
educação ambiental intentada a romper com o padrão societário atual que gera/reflete uma crise socioambiental.

Não que entidades corporativas não possam estar ligadas à educação ambiental, pelo contrário; é importante que elas o façam e contribuam nas reflexões sobre o padrão societário vigente, inclusive desenvolvendo atividades de educação ambiental em suas entidades.

Cabe refletir, sobretudo, sobre os reais interesses destas entidades na institucionalização de nossas políticas públicas de educação ambiental, quando observamos a presença do Banco Mundial, por exemplo. Por que uma entidade como esta deveria estar presente e ajudar a nortear políticas educativas? A que $(\mathrm{m})$ ela serve?

\section{A necessidade do diálogo}

Em todos os trabalhos encontrou-se a necessidade de que os agentes/atores que são encontrados nas diferentes etapas de institucionalização das políticas públicas de educação ambiental (e educativas como um todo) dialoguem entre si, de modo a buscar uma gestão integrada.

É preciso que os diferentes agentes/ atores comuniquem-se e integremse permitindo que as políticas públicas criadas explicitem mediações entre os diferentes setores sociais, e não sejam apenas o reflexo de um setor. Desta forma, "(...) as ações governamentais devem ser elaboradas para a sociedade e, acima de tudo, com a sociedade, ou seja, devem ser concebidas levando em conta os desejos da coletividade", sendo "(...) necessário o estabelecimento de canais e espaços que promovam o diálogo para a efetiva participação da sociedade - organizada em grupos de interesse - na formulação, acompanhamento e avaliação das políticas públicas (Tr.24D, p. 97, grifo nosso).

Para isso, deve haver inclusive um aparato legal que as assegure, como, por exemplo, na PNEA, a qual “(...) reclama a participação do poder público, das organizações não-governamentais, entidades de classes e empresas públicas e privadas" (Tr.18D, p. 66).

Ou como no ProFEA, no qual estão clamadas as "tantas experiências que devem ser alimento para as práticas da educação ambiental, [e os] tantos sujeitos que devem ser entendidos como sujeitos da educação ambiental" (p. 
16) .(Tr.23T, p. 97). Desta forma, o diálogo entre os agentes ajudaria a sanar as “(...) diferenças entre a educação ambiental almejada no discurso e a praticada nas escolas, bem como às barreiras que impedem sua concretização", uma vez que "o discurso [oficial] está distanciado da realidade do sistema educacional brasileiro" (Tr. 15D, p. 03, grifo nosso).

Sem diálogo e participação, o que se propõe no texto da política pública instituída pode estar distante do necessário para que o problema /conflito seja de fato resolvido, criando, assim, políticas "esvaziadas", que não solucionam problemas e em nada contribuem com a organização social.

As políticas públicas não devem refletir opções ideológicas daqueles que estão no governo apenas, mas, pelo contrário, devem buscar o bem-estar social/ coletivo. Assim, as políticas não devem ser apenas instrumentos coercitivos da sociedade, sendo apenas esta normatizada pelas políticas públicas criadas.

Para que os desejos e interesses de mais parcelas sociais sejam incorporados nas políticas educacionais é necessário o estabelecimento de canais de comunicação, tais como em comissões, conselhos e comitês.

Considerações finais

Como consequência da vertiginosa produção de pesquisas em educação ambiental, as pesquisas de estado da arte permitem que se observem contextos de produção e contribuições de pesquisadores em suas investigações, assim, como as lacunas na área que ainda permitem novas indagações.

Projetos como "A EDUCAÇÃO AMBIENTAL NO BRASIL: análise da produção acadêmica (dissertações e teses)" (CARVALHO et al., 2012), tem grande relevância, pois além de sistematizarem a produção de pesquisas na área, contribuem com a configuração de um catálogo gratuito, permitindo acesso a um enorme acervo de trabalhos. O que por sua vez possibilita a observação do já foi produzido, diálogos possíveis entre as pesquisas e as lacunas ainda em aberto, fomentando desenvolvimento de novas investigações.

Com relação aos agentes/atores envolvidos nos processos de elaboração e implementação de políticas públicas, sugere-se que não apenas 
os gestores governamentais integrem os processos de formulação das políticas, mas que outros setores sejam convidados para também fazê-lo, integrando processos decisórios.

Nesse sentido, são necessários mais espaços dialógicos entre diferentes setores sociais governamentais e não-governamentais, nas quais os últimos possam participar diretamente dos processos decisórios, permitindo que se materializem seus interesses e opções ideológicas e buscando que os mesmos sejam incorporados nas políticas públicas institucionalizadas (NERY-SILVA, 2015).

$\mathrm{Na}$ educação isto permite que se institua, inclusive, uma educação ambiental com o caráter de uma educação popular, como aquele que poderia articular de forma democrática, diversas esferas de ação da/na sociedade civil, "construindo estruturas de coesão e identidade política nas pautas dos diversos sujeitos e espaços de educação" (NARITA, 2014, p. 51).

Daí o grande desafio aos gestores públicos e aqueles que os elegeram: concretizar espaços mais participativos, dialógicos e democráticos que permitam que os interesses sociais coletivos sejam refletidos nas políticas públicas institucionalizadas. É necessário que os setores sociais que poderão ser afetados direta ou indiretamente pelas políticas educativas instituídas sejam consultados: "que se convoquem os educadores e educandos para tratar de educação, que se convoquem os cidadãos para construir a cidadania. E mais, ter o efetivo controle social sobre elas" (NERY-SILVA, 2015, p.136).

\section{REFERÊNCIAS BIBLIOGRÁFICAS}

AZEVEDO, J. M. L.de. A educação como política pública. 3. Ed., v. 56. Campinas: Autores Associados, 2004. (Polêmicas do Nosso Tempo)

BARDIN, L. Análise de Conteúdo. Lisboa: Edições 70, 2011.

BIASOLI, S. A. Institucionalização de políticas públicas de educação ambiental: subsídios para uma política do cotidiano. 234 p.Tese (Doutorado em Ciências Ecologia Aplicada) - Centro de Energia Nuclear na Agricultura, Universidade de São Paulo, Piracicaba, 2015. 
BITAR, A. L. Pesquisa em educação ambiental: a atividade de campo em teses e dissertações. 172 f. 2010. Dissertação (Mestrado em Educação) Instituto de Biociências, Universidade Estadual Paulista "Júlio de Mesquita Filho", Rio Claro, 2010.

BRANDÃO, C. R. O que é educação. São Paulo: Editora Brasiliense, 1981.

CAPELLA, A. C. N. O papel das ideias na formulação e políticas públicas. In: Encontro de administração pública e governança. - ENAPEG, 2006, São Paulo. Anais... São Paulo: Associação Nacional de Pesquisa em Administração, 2006.

Perspectivas teóricas sobre os processos de formulação de políticas públicas. In: HOCKMAN, G.; ARRTECHE, M.; MARQUES, E. (org). Políticas públicas no Brasil. Rio de Janeiro: Ed. FIOCRUZ, 2007, p. 87-122.

CARVALHO, L. M.; TOMAZELLO, M. G. C.; OLIVEIRA, H. T. Pesquisa em educação ambiental: panorama da produção brasileira e alguns de seus dilemas. Cadernos Cedes, Campinas, v. 29, n. 77, p. 13-27, jan./abr. 2009.

CARVALHO, L. M. et al. A educação ambiental no Brasil: análise da produção acadêmica - teses e dissertações. CNPq: Relatório Científico. Rio Claro: Unesp; Campinas: Unicamp; Ribeirão Preto: USP, 2013.

CAVALARI, R. M. F.; SANTANA, L. C.; CARVALHO, L. M. Concepções de Educação e Educação Ambiental nos Trabalhos do I EPEA. Pesquisa em Educação Ambiental, Rio Claro, v. 1, n. 1, p. 141-173, 2006.

DIAS, G. F. Os quinze anos da educação ambiental no Brasil: um depoimento. Em Aberto, Brasília. v.10, n. 49, p.3-14, jan./mar. 1991.

DYE, T. Understanding Public Policy. Englewood Cliffs: Prentice-Hall, 1984.

FERRARO-JUNIOR, L. A. Dialogar e digladiar: entre a conflagração e a contribuição do campo da pesquisa sobre políticas públicas de educação ambiental. Pesquisa em Educação Ambiental, Rio Claro, v. 7, n. 2, p. 133145, 2012.

FERREIRA, N. S. de A. As pesquisas denominadas "Estado da arte". Educação \& Sociedade, Campinas, ano XXIII, n. 79, p. 257-272, ago. 2002.

FRACALANZA et al. Educação Ambiental no Brasil: panorama inicial da produção acadêmica. In: Encontro Nacional de Pesquisa em Educação em Ciências - ENPEC, 5, 2005, Bauru. Anais... Bauru: Associação Brasileira de Pesquisa em Educação em Ciências, 2005.

GIRON, G. R. Políticas públicas, educação e neoliberalismo: o que isso tem a ver com cidadania? Revista de Educação da PUC-Campinas, Campinas, $\mathrm{n}$. 24, p. 17-26, junho 2008. 
GODOY, A. S. Introdução à pesquisa qualitativa e suas possibilidades. Revista de Administração de Empresas, v. 35, n. 2, p. 57-63, mar./abr. 1995.

GOHN, M. G. Movimentos sociais na contemporaneidade. Revista Brasileira de Educação, Rio de Janeiro, v. 16, n. 47, maio/ago., 2011.

GUIMARÃES, M.; OLABARRIAGA, N.; TONSO, S. A pesquisa em políticas públicas e educação ambiental. Pesquisa em Educação Ambiental, Rio Claro, v. 4, n. 2, p. 215- 227, 2009.

HÖFLING, E. M. Estado das políticas (públicas) sociais. Cadernos Cedes, Campinas ano XXI, n. 55, p. 30-41, nov./ 2001.

KATO, D. S. O conceito de "ecossistema" na produção acadêmica brasileira em educação ambiental: construção de significados e sentidos. 2014. 233 f. Tese (Doutorado em Educação Escolar) Faculdade de Ciências e Letras, Universidade Estadual Paulista "Júlio de Mesquita Filho", Araraquara, 2014.

O significado pedagógico da contextualização para o Ensino de Ciências. 116 f. Dissertação (Mestrado em Educação), Universidade de São Paulo, Ribeirão Preto, 2007.

KAWASAKI, C. S.; CARVALHO, L. M.; ROSA, A. V.; BONOTTO, D. M. B.; OLIVEIRA, H. T.; CINQUETTI, H. S. C.; SANTANA, L. C.; CAVALARI, R. M. F. A pesquisa em educação ambiental nos EPEAs (2001- 2007): a natureza dos trabalhos, contextos educacionais e focos temáticos. Pesquisa em Educação Ambiental, Rio Claro, v. 4, n. 2, p. 147- 163, 2009.

MEGID NETO, J. Educação ambiental como campo de conhecimento: a contribuição das pesquisas acadêmicas para sua consolidação no Brasil. Pesquisa em Educação Ambiental, Rio Claro, v. 4, n. 2, pp. 95-110, 2009.

NARITA, F. Z. Temas, conceitos e processos em educação popular: uma discussão a partir das Ciências Sociais. Cadernos CIMEAC, Ribeirão Preto, v.4, n. 2, p. 41-57, 2014.

NERY-SILVA, A. C. Educação ambiental e políticas públicas nas dissertações e teses de educação ambiental no Brasil: análise dos processos de elaboração e implementação. 2015. 189 f. (Mestrado em Educação) - Instituto de Biociências, Universidade Estadual Paulista "Júlio de Mesquita Filho", Rio Claro, 2015.

PALMIERI, M. L. B. Os projetos de educação ambiental desenvolvidos nas escolas brasileiras: análise de dissertações e teses. $2011.189 f$. Dissertação (Mestrado em Educação) - Instituto de Biociências, Universidade Estadual Paulista “Júlio de Mesquita Filho”, Rio Claro, 2011.

PINHEIRO, P. S. O conceito de Sociedade Civil. Disponível em: <www2.dbd.- 
PUC-Riobr/pegamum/teses abertas>. Acesso em: 1 jul.2015.

REIGOTA, M. O Estado da Arte da Pesquisa em Educação Ambiental no Brasil. Pesquisa em Educação Ambiental, Rio Claro, v. 2, n. 1, p. 33-66, 2007.

REIS, D. A. Compreensões elaboradas pelo campo da educação ambiental sobre o tema mudanças climáticas: análise de dissertações e teses brasileiras. 2013. 217f. (Mestrado em Educação) - Instituto de Biociências, Universidade Estadual Paulista “Júlio de Mesquita Filho", Rio Claro, 2013.

SANTANA, L. C. Educação ambiental: de sua necessidade e possibilidades. In: International Workshop on Project Based, 2005, Guaratinguetá. PBLTech 2005 - International Workshop on Project Based., 2005, p.1-14.

Pesquisa em Educação Ambiental e Políticas Públicas: Apontamentos e memórias de um processo. Pesquisa em Educação Ambiental, Rio Claro, v. 9, n. 1, p. 156-168, 2014.

SANTOS, B. S. Reinventar a democracia: entre o pré- contratualismo e o póscontratualismo. In: HELLER, A. et al. (orgs). A crise dos paradigmas sociais e os desafios para o século XXI. Rio de Janeiro: Contraponto, 1999, p. $33-75$.

SORRENTINO, M. Desenvolvimento sustentável e participação: algumas reflexões em voz alta. In: CASTRO, R. S.; LAYRARGUES, P. P.; LOUREIRO, C. F.B. (orgs). Educação Ambiental: repensando o espaço da cidadania. 5. ed. São Paulo: Cortez, 2011. p. 19-25.

SOUZA, C. "Estado do campo" da pesquisa em Políticas públicas no Brasil. Revista Brasileira de Ciências Sociais, São Paulo, v. 18, n. 51, p. 15-20, fev./2003.

. Estado da arte da Pesquisa em Políticas Públicas. In: HOCKMAN, G.; ARRTECHE, M.; MARQUES, E. (org). Políticas públicas no Brasil. Rio de Janeiro: Ed. FIOCRUZ, 2007, p. 65-86.

SOUZA, H. A. L. A "ética ambiental" na produção teórica (dissertações e teses) em educação ambiental no Brasil. 2012. 200p. Dissertação (Mestrado em Educação) - Instituto de Biociências, Universidade Estadual Paulista "Júlio de Mesquita Filho", Rio Claro, 2012.

ZUPELARI, M. F. Z. O debate modernidade/pós-modernidade e a crise socioambiental: um estudo sobre teses e dissertações brasileiras em Educação Ambiental. 2014. 165 p. Dissertação (Mestrado em Educação) Instituto de Biociências, Universidade Estadual Paulista "Júlio de Mesquita Filho", Rio Claro, 2014. 